\title{
LA UNIVERSIDAD DE CHILE ANTE EL PROYECTO DE REFUNDACIÓN ECONÓMICA E IDEOLÓGICA DE CHILE MEDIANTE EL USO DE LA FUERZA Y LA VIOLENCIA
}

\author{
Ennio Vivaldi ${ }^{1}$
}

El golpe de Estado de 1973 afectó a la Universidad de Chile al menos en tres modalidades de embates y conminaciones. La primera se expresa en las interacciones directas del régimen dictatorial con ella, es decir, la intervención en cuanto tal, los rectores delegados, el cercenamiento de las sedes, las persecuciones y exoneraciones. La segunda modalidad se manifiesta en el desmantelamiento del Estado chileno que el régimen dictatorial implementa. Destruir el Estado chileno representa la destrucción de la obra que había constituido la razón de ser de la Universidad de Chile. Así como un artista en el renacimiento, obligado a elegir entre que destruyan su obra o que lo maten a él, hubiera optado por la preservación de su arte; análogamente la destrucción del Estado chileno es una forma apenas indirecta y quizás más amplia y profunda de destrucción de nuestra Universidad, cuyo sentido y razón de ser, explícitamente establecido al momento de su fundación, era la creación y desarrollo para la patria recientemente independizada de un Estado autónomo. La tercera modalidad, más tenue y sutil a la vez que infinitamente más vasta y aleve, se difumina en el conjunto de valores que el régimen militar va imponiendo cual auténtica dictadura ideológica y que, en mi opinión, admito que pueden haber otras, constituyen una apología del egoísmo y la mezquindad, una negación activa del compromiso y la pertenencia social, y, en su forma de analizar cualquier situación, un arrogante desprecio por la historia y los contextos. Se comprende fácilmente que tales valores son muy difíciles de compatibilizar con el lema de "una Universidad cuyo norte sea Chile y las necesidades de su pueblo". Es muy distinto un contexto civil en que el éxito sea el acumular el mayor beneficio para uno mismo a otro contexto civil que tenga por referencia esa búsqueda no de enriquecimiento material propio sino de una trascendencia que, por graficarla de algún modo, es expresada en la frase (permítaseme un tributo a la influencia que Francia tuvo en el desarrollo de la educación chilena en los últimos dos siglos) aux grands hommes la patrie reconnaissante. Es este espíritu de servicio desinteresado y generoso a la Nación en su conjunto el que inspirara a quienes, desde nuestra Universidad, crearan y desarrollaran los sistemas educacional, sanitario, jurídico, tecnológico y científico para Chile a lo largo de toda nuestra vida republicana.

1. Médico, especialista en neurofisiología y trastornos del sueño, investigador del Instituto de Ciencias Biomédicas de la Facultad de Medicina de la Universidad de Chile. Antes lo fue del INTA. En los años 80 integró la Mesa Directiva de la Asociación Andrés Bello y de la Asociación de Académicos de la Universidad de Chile. Fue el primer vicepresidente del Senado Universitario. Actualmente es vicedecano de la Facultad de Medicina de la Universidad de Chile. 
Estas tres dimensiones del ataque a la Universidad de Chile generaron correspondientes defensas en las que participamos académicos, funcionarios y estudiantes. Durante la crisis de Federici, rector designado civil, el titular de un diario citando a un economista muy vinculado al régimen afirmaba "Si cae Federici cae Pinochet". Desde luego que la relación entre antecedente y consecuente parece una extrapolación exagerada pues, en un tiempo en que no había otra fuerza reconocida que la de las armas —armas demostradamente prontas para entrar en acción apenas se juzgara conveniente-, resultaba ridículo suponer que la estabilidad de un régimen sostenido por cuanto tanque, avión de combate o nave de guerra existiera en Chile, pudiera verse afectada por lo que le ocurriera o no a un rector designado. Sin embargo, lejos de ser una frase ridícula, puede que haya habido una notable perspicacia en el economista autor de la cita. Lo que él en realidad estaba sugiriendo era que si el Gobierno no era capaz de doblegar a la Universidad de Chile, bastión de los valores que el régimen se había propuesto erradicar, entonces eso significaba que la gran gesta refundacional, en lo que hacía referencia a la necesaria transformación profunda de la ideología de nuestra sociedad, había fracasado. Y eso no podía permitirse. Ergo, no poder no permitir lo que no podía permitirse, resultaba grave y podía tener las peores consecuencias. Bien pensado.

Efectivamente, sea por relación causal, sintomática o por mera secuencia temporal, cumpliendo la advertencia del preclaro economista, se fue Federici y sobrevino el fin del régimen. Pero entonces habríamos de aprontarnos para asumir una verdad tan triste como insoslayable, pues mientras nos enfrentábamos al régimen dictatorial nunca pensamos que podíamos perder ninguna de estas tres confrontaciones mencionadas: la defensa de la Universidad, la del Estado chileno y la de una ideología solidaria. Para nosotros un mundo regido para siempre por las ideas que se nos imponían y a las que nos oponíamos era tan incomprensible e irracional que, por ese curioso razonamiento inverso que sigue quien se involucra en una contienda, concluíamos que era imposible que perdiéramos. A decir verdad, la primera vez que pensamos que podíamos perder fue poco después que creímos que habíamos ganado.

\section{LA DEFENSA DE LA UNIVERSIDAD DE CHILE}

La escena que paso a relatar, pues uno quisiera retransmitir el clima de la época y las emociones que vivíamos, ocurre en los primeros días de julio de 1986, durante un paro nacional. El día de mi relato las Fuerzas Armadas habían ingresado violentamente a nuestra Facultad de Medicina persiguiendo a estudiantes. El hall de ingreso del Departamento de Fisiología y Biofísica estaba atiborrado. Había académicos y funcionarios, estaba un grupo de carabineros (con la ya habitual vestimenta protectora de aspecto robótico) al mando de un teniente joven y nervioso, todos ellos apuntando con sus armas, y, contra la pared, estaba un grupo de estudiantes que había sido sacado de las salas de seminario por los carabineros. Los carabineros afirmaban que los estudiantes habían llegado allí buscando refugio y nosotros sosteníamos que solo estaban aprovechando el paro para tomar clases de recuperación. Yo estaba a muy corta distancia de los 
estudiantes. El teniente alzó la voz para declarar que los estudiantes estaban detenidos y dio la orden de que debían salir. Silencio. El teniente repitió la orden. Alguien, académico o funcionario, pidió que los estudiantes pudieran decir sus nombres antes de salir. Los estudiantes comenzaron a decir sus nombres en voz alta. El teniente volvió a repetir la orden. Algunos académicos y funcionarios comenzaron lentamente a desplazarse para abrir un pasillo por el cual los estudiantes pasarían hacia la puerta de salida. Yo estaba junto a los estudiantes, les miraba las caras. En ese momento, resonó en todo el hall una voz de mujer, recuerdo nítidamente la vibración de esa voz que llegaba originándose a mis espaldas y que hacía remecerse el lugar entero; la recuerdo con su intensidad y con su infinita carga de angustia y emoción. Y se escuchó retumbar por la acústica del hall: "¿Vamos a dejar que se lleven a nuestros estudiantes?", breve pausa, y entonces, con aun

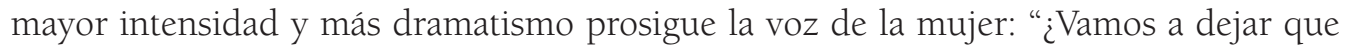
se lleven a nuestros estudiantes y nosotros no vamos a hacer nada?". Al girar la cabeza vi que quien había hablado desde el otro extremo del hall junto a la escala era la Dra. Ann Wallace. Por un momento nos inmovilizamos, todos nos paralizamos. Las palabras parecían haber quedado reverberando. En ese momento de tiempo suspendido, el Dr. Raúl Godoy se acercó a la puerta y disimuladamente la empujó lo justo para cerrarla. La cerradura era eléctrica y la electricidad había sido cortada hacía rato para todo el sector. Cuando los carabineros se encontraron con la puerta cerrada pidieron una llave, la que obviamente nadie tenía. El teniente comenzó a patear la cerradura para abrir la puerta. Otros carabineros imitativamente dieron patadas, pero la cerradura parecía haberse abanderizado también ella con los estudiantes, y con firmeza notable. Pasó un largo rato antes que, intervención mediante del decano de la época y de un cerrajero (representando respectivamente al espíritu y a la materia, supongo), se abriera la puerta. Apenas eso ocurrió los carabineros se retiraron rápidamente, olvidándose de los estudiantes.

Para quienes ahí estuvimos — conversé con algunos en estos días- recordar esa escena es volver a vivir la emoción colectiva que generó. Por supuesto, la situación podía resultar tan metafórica como cada cual quisiera. La voz de mujer angustiada pero firme, emocionada pero intensa y nítida, me evoca aún hoy un sentido de defensa ya no de personas e instituciones sino más bien de una estirpe, de un linaje, de la condición misma de intelectualidad, de saber, de historia, de ciencia. Además del cariño por esos estudiantes concretos, estaba quizás también la certeza de que lo que estaba bajo amenaza podía ser la supervivencia de nuestra condición universitaria, al menos como la habíamos aprendido e incorporado en esta, nuestra Universidad. La supervivencia de nuestra condición universitaria, en cuanto guardaba relación con nosotros, con esos estudiantes, y con quienes estaban por venir en décadas futuras. Así, la resistencia al régimen dictatorial parecía retrotraernos a momentos primigenios. Era demasiado básico lo que teníamos que amparar. Como si hubiéramos retrocedido tanto que la línea de defensa se iba acercando casi a la noción de civilización.

Al día siguiente una patrulla militar habría de detener a dos jóvenes, Carmen Gloria Quintana y Rodrigo Rojas DeNegri. Rodrigo, fotógrafo educado en Estados Unidos, colaboraba en un laboratorio de nuestro Departamento de Fisiología y Biofísica mientras preparaba su prueba de ingreso a la Universidad. Los militares habían vertido un bidón 
de bencina sobre los dos jóvenes, les habían prendido fuego y los habían transportado a la periferia de Santiago para abandonar ahí sus cuerpos vivos. (Como tantas cosas, uno se sigue negando a aceptar que esto pueda haber ocurrido, uno debe haber entendido mal lo que acaba de leer). Supongo que quemar vivas a dos personas pretendía ser un gesto aleccionador para disuadir de hacer barricadas incendiarias durante las protestas. En cualquier caso, se redoblaron las protestas y se hizo más despiadada la represión.

Transcurría esa jornada de enfrentamientos cuando vinieron a buscarnos estudiantes porque habían ingresado soldados con pintura y armas de combate a la Escuela de Salud Pública. Al acercarnos por el pasillo a la ESP volveríamos una vez más a quedar atónitos. Nos detuvimos paralogizados, parecía que estuviéramos ante la puesta en escena de un director o coreógrafo. En el hall de la ESP, configurando una pulcra disposición geométrica, como un caleidoscopio, separados por un poco más de un metro uno de otro en un patrón repetitivo que cubría todo el hall, estaban tendidos en el suelo boca abajo y con las extremidades extendidas, los estudiantes. Al lado derecho de cada alumno, a la altura de su hombro, estaba parado un uniformado con un arma larga, la punta de cuyo cañón se mantenía muy cerca de la cabeza del estudiante.

Recuerdo que, al momento del Golpe, el Director de la Escuela de Salud Pública era uno de los docentes más abnegados, talentosos y rigurosos que yo recuerde: el Dr. Hugo Behm Rosas. Fue detenido y se desconoció su paradero hasta que se pudo ubicar en Ritoque. Partió al exilio en agosto de 1975. El decreto de la Rectoría de la Universidad de Chile de $1^{\circ}$ de abril de 1974 había fundamentado la aceptación de su renuncia con los siguientes tres vistos:

"a) La necesidad de garantizar una armónica convivencia universitaria que permita el libre e íntegro desarrollo de las distintas funciones universitarias a nivel académico, no-académico y estudiantil.

b) El imperativo de lograr una docencia objetiva y pluralista; evitar el uso de la función universitaria con fines proselitistas y sectarios; exigir el cumplimiento efectivo de los planes y programas propios de la función universitaria e imponer el cabal cumplimiento de las obligaciones y deberes que conlleva la calidad de funcionario de la Universidad de Chile, y

c) El decreto ley $N^{\circ} 111$, de 9 de Noviembre de 1973 del Ministerio de Educación"

Dicho sea de paso, un magnífico ejemplo de newspeak orwelliano. Alfredo Jadresic, académico de brillante carrera y decano protagonista cardinal de la Reforma en nuestra Facultad, también fue detenido, recluido en el Estadio Nacional y enviado al exilio. En su biografía (REF. 1) expone cómo repercuten en la Facultad de Medicina la Reforma, el gobierno de Allende y el Golpe militar. Carlos Lorca, otro gran protagonista de la Reforma, presidente del Centro de Estudiantes de Medicina, posteriormente diputado de la República, habría de ser detenido en junio de 1975, torturado y hecho desaparecer. Enrique Paris y Jorge Klein, ambos académicos de nuestra Facultad y también muy notables participantes del proceso de Reforma, fueron también hechos desaparecer tras ser detenidos en La Moneda donde acompañaban a Allende (REF. 2).

En los días tempranos tras el golpe venían efectivos de la FACH desde Colina a formar piquetes en las salidas. Había que identificarse ante ellos para que comprobaran que no 
se estaba en los listados de nombres buscados que traían consigo. También comenzaron los allanamientos buscando por todas partes, abriendo cada casillero, concentrando a todo el mundo en la cancha de fútbol. Los allanamientos adquirieron una programación estereotipada con los uniformados formándose en el Cerro Blanco y desde ahí bajando para copar la facultad y el hospital.

En la primavera de 1973 Santiago era una ciudad ocupada, un sol frío sobre edificios grises, piquetes de soldados vigilando las calles y revisando a las personas que transitaban por una ciudad que ya se iba transformando en otra. Hace algún tiempo, me impactó mucho ver el documental de Juan Antonio Bardem sobre la muerte de García Lorca, por la veracidad con que el director lograba recrear la atmósfera propia de la instauración de una dictadura militar omnipotente, tal como la vivimos aquí en Chile. Ese perplejo sometimiento a tramas de decisiones sobre las cuales no teníamos cómo influir y que, tan exuberantes en fuerza como vacías en racionalidad, determinaban nuestros aconteceres. Literalmente una miríada de tragedias griegas desplazándose por una ciudad. Un absurdo casi onírico lo abarcaba todo y desplazaba a la sensatez. Lo que nos habría de ocurrir no dependía de lo que habíamos hecho, mucho menos de que nos autocalificáramos de bien o mal intencionados, sino de designios para nosotros inasibles. Quizás se parece algo a cómo ve la vida un niño, de ahí la regresión infantil de las sociedades viviendo bajo dictaduras. La prensa alababa con impudicia cualquier dicho de cualquier autoridad militar como una rara intersección de lo intelectualmente sublime y la razón moral superior que inspira al desinteresado defensor de la patria. En algún momento Pinochet ingresó al salón de honor de la Casa Central haciendo gala de su condición de patrono de nuestra Universidad. Difícilmente el Chile postgolpe era un entorno apropiado para que se desplegara cual bandera al viento el vuelo y la autonomía intelectual que se espera de una Universidad.

Pero vuelvo a situarme a la entrada del hall de la Escuela de Salud Pública, con los estudiantes en el suelo, con los militares apuntándolos y con la estética caleidoscópica. Por incredulidad, perplejidad y amargura decidimos con Rosa Devés, Norbel Galanti y Carlos Valenzuela escribir una carta que publicó la revista Nature (REF. 3). Era la necesidad de intentar de explicarle al mundo lo que nosotros mismos no podíamos entender. En el párrafo final señalábamos: "Pensamos que estos eventos deberían estimular la reflexión y la acción de la comunidad académica internacional. En las ciencias experimentales, la comprensión de conceptos de amplia y profunda relevancia se logra no mediante la observación de los fenómenos en su contexto habitual, sino más bien llevándolos a condiciones extremas. En Chile, la relación entre universidad, sociedad y régimen político ha sido llevada hoy a un extremo grotesco".

\section{EL ESTADO DE LA UNIVERSIDAD}

Así como al encender un computador lo primero que este hace es cargar un sistema operativo que le permita interactuar con su entorno, o al iniciar la construcción de un edificio se planta una torre-grúa en torno a la cual se orquestará la edificación, el 
país recién independizado creó la Universidad de Chile. La República y la Universidad coevolucionaron de modo que lo que le fue ocurriendo a una resultaría incomprensible si se desconociera lo que le iba sucediendo a la otra. Fluidamente, en el entorno mundial de la postguerra, se destaca el rol del Estado chileno en impulsar el desarrollo económico y en garantizar al conjunto de la población derechos considerados básicos como la educación y la salud. Si bien sus propios impulsores podrían haber dudado en admitirlo, en retrospectiva y más allá de la retórica, el proyecto de la Unidad Popular era en gran medida una profundización de un conjunto de tendencias históricas reafirmadas al empezar la segunda mitad del siglo veinte. Esta observación, por supuesto, goza del beneficio de compararla y contrastarla con el otro proyecto, el brutalmente disruptivo, que se echaría a andar bajo el gobierno militar. Este último tiene una historia que arranca ya en la década de los años 50 cuando se inicia una relación entre economistas de la Universidad Católica de Chile y de la Universidad de Chicago. Juan Gabriel Valdés ha descrito elocuentemente esta relación en un libro excepcional en al menos dos sentidos de la palabra: sobresaliente e infrecuente (REF. 4). Puede de paso señalarse que los fundamentos jurídicos del nuevo régimen, además de los económicos, coincidentemente tuvieron la autoría de un grupo proveniente de esa Universidad, pero no hubo un rol de la institución universitaria como tal, a diferencia de lo ocurrido con la Universidad de Chile en el modelo de sociedad anterior. De hecho, ese rol no ha sido sugerido ni siquiera cuando, después de la transición de 1989, parecía haber un amplio consenso político respecto a las bondades de modelo heredado.

La cuestión de la continuidad y discontinuidad es relevante para tratar de entender las alternativas históricas que nos fueron conduciendo al actual modelo de sociedad. De hecho, al fallido proyecto de transición al socialismo llegamos por elecciones democráticas, mientras que al neoliberal lo hicimos mediante un golpe de Estado. Una pregunta inquietante es cuán compatible era la instauración en Chile del modelo neoliberal que se venía estudiando e incubando con la tradición democrática del país. Tal como ocurrieron las cosas, tras elegirse un presidente que se sentía mandatado para instaurar un modelo socioeconómico socialista, se generó — con la distribución de responsabilidades entre Gobierno y oposición que cada cual quiera imputar - una tensión social que permitió que las Fuerzas Armadas tomaran el poder por la fuerza, suponemos convencidas de la insinceridad del presidente en su declarado compromiso con la democracia; y todo ello en el contexto de extremo bilateralismo del mundo entonces. La extrema violencia practicada para instalar y mantener el nuevo régimen, totalmente fuera de contexto respecto a cualquier capacidad de ejercer la fuerza por parte de los depuestos, es un indesmentible testimonio de la fuerza no material de estos, del arraigue que las ideas que se quería aplastar tenían en la población, así como de la previsible dificultad con que esta aceptaría las nuevas normativas socioeconómicas. No podemos saber qué hubiera ocurrido si en 1970 hubieran triunfado Jorge Alessandri o Radomiro Tomic, pero una inevitable especulación instalada es si acaso la instauración del modelo neoliberal que se incubaba no hubiera exigido antes o después la supresión de la democracia. Caría preguntarse: ies este un modelo al cual un país como Chile solo podía llegar por una dictadura severa que limite drásticamente las libertades individuales y colectivas? 
Respecto a la instauración concreta ocurrida en Chile sí que no hay especulación: la redistribución de la riqueza y el traspaso de capitales del sector público al privado exigían la abolición de sindicatos y organizaciones estudiantiles así como de la libertad de prensa y de la autonomía universitaria. El desprecio de los creadores del modelo por los valores históricos de nuestra democracia fue proclamado a viva voz. Por ejemplo, los sindicatos ya no eran los heroicos trabajadores que luchan por el pan de sus hijos con toda la carga emocional de una novela de Émile Zola, ahora más bien habían pasado a ser potenciales matones que había que mantener a raya pues pretendían interferir con la libertad del mercado. Se instala sin recato una visión peyorativa de los políticos en democracia, quienes buscan usar el Gobierno para someter el interés colectivo al partidario, en oposición diametral a los economistas neoliberales, quienes aplican criterios estrictamente técnicos, científicamente validados. Cualquier visión o modelo alternativo es absurdo y ahistórico. De nuevo, pocas cosas más peligrosas para las universidades que las verdades absolutas en el poder.

En 1973 vivimos el inicio de una transición que conllevaba un cambio paradigmático donde el nuevo orden minimizaba el rol de Estado no solo en la economía sino en todas las esferas de la sociedad, y muy marcadamente en educación y salud. El nuevo paradigma deificaba el rol del individuo, por lo que el desarrollo del colectivo se habría de basar en el afán de lucro personal en un contexto de competencia. Las bondades de la competencia eran objeto de una fe dogmática absoluta. Educación y salud pasaron a ser simples bienes comercializables. En algún momento muchos hicimos uso de la ironía y el sarcasmo para evidenciar tales despropósitos, por ejemplo, sugerir que en vez de tener "alumnos" pasaríamos a tener "clientes", o incluso, para exagerar el absurdo a grados extremos, que el órgano regulador de las universidades sería el Servicio Nacional del Consumidor (SERNAC). Al poco tiempo no se titubeaba en referirse a los alumnos como clientes y el SERNAC se transformaba efectivamente en un ente que dirimía acerca de la idoneidad de las universidades. No había diferencia alguna en los criterios fundamentales con que se manejaba una Universidad al compararla con cualquier (otra) industria. Los considerandos gerenciales eran los mismos. Chile estaba pasando a ser para el mundo capitalista lo que Rumania había sido para los socialismos reales. Nos transformábamos en una caricatura grotesca, impensable para cualquier país capitalista serio de Europa occidental o para Estados Unidos. (Piénsese, por ejemplo, en el rol que en este último tiene la esfera pública en la investigación biomédica, o en sus entes regulatorios que determinan la formación de especialistas médicos en cantidad y calidad, o en lo inimaginable que sería privatizar MEDLINE, la base de datos bibliográficos biomédicos gratuita que podría ser un negocio de utilidades fabulosas).

Pocas decisiones más trascendentes para el futuro de la educación terciaria en Chile que la de expandir la matrícula por vía de la creación de universidades privadas. En primer lugar, una pregunta demasiado cándida para que pudiera ser formulada: si se ha de aumentar la matrícula, ipor qué no hacerlo asignándoles la tarea y los medios a las universidades demostradamente idóneas en el cumplimiento de esa tarea: la Universidad de Chile, la Pontificia Universidad Católica, la Universidad de Concepción, y tantas otras? La respuesta está en que idóneo ya no significaba lo que solía significar. El modelo había 
reducido todo a la condición unidimensional del dinero. Las infinitas dimensiones involucradas en áreas tan vastas del quehacer humano como la educación o la salud, se reducían a una: el lucro. Pasábamos a razonamientos inéditos y delirantes. Ejemplo: en función de cuánto más aspira a ganar el que tiene un título por el hecho de tener ese título, se puede determinar cuánto estaría dispuesto a pagar para obtenerlo, considerando esta como una inversión en sí mismo. Se escuchaban argumentos fantásticos (al menos la primera vez que se oían, después nos fuimos acostumbrando): "Es preferible que una familia gaste su dinero en una institución chilena que otorga educación universitaria, aunque no sea tan buena, a que ese dinero lo gaste en suntuarios importados". Qué otra cosa podía uno decir más allá de confesar que aquello nunca se le había ocurrido espontáneamente. Y una pregunta que nos formuláramos al principio pero que se terminó por trivializar en novedosas taxonomías basadas en adjetivos tan específicos como "complejas": ipueden ser consideradas universidades instituciones donde no se hace investigación científica? Hubo un tiempo en que la respuesta era no.

Por supuesto que no todas las universidades creadas a partir de la Ley de 1981 son equivalentes, más aun, en la medida en que algunas universidades privadas representaban grupos ideológicos importantes, esperablemente se propusieron estar en un plano intelectual a la altura de lo representado. Sin embargo, la "expansión de la matrícula universitaria" como la entendieron muchas de las universidades creadas en el nuevo marco legal, representa uno de los negocios más cuestionables jamás establecidos. Un tráfico consistente en vender a familias la ilusión de una educación universitaria que, en realidad, no cumple con ninguno de sus dos requisitos definitorios: un ambiente formativo que abra una nueva visión de mundo y un título efectivamente validado que permita ejercer una profesión.

María Olivia Mönckeberg, en otro libro excepcional (REF. 5), relata el origen del sistema universitario privado, su vínculo con el empresariado y los dirigentes del régimen de Pinochet, y su posterior cooptación de los políticos post-1990, como rápidamente habría de quedar en evidencia. Porque, cuando el Gobierno concertacionista de comienzos de los 2000 se enorgullece al proclamar el alto número de estudiantes universitarios que lo son en primera generación, es decir que ni sus padres ni abuelos habían cursado estudios universitarios, esa declaración se hace con el orgullo de un logro sentido como propio. Quienes recordamos el sistema pre-1973, siendo selectivo en el ingreso, al menos era capaz de incorporar a sectores de muy heterogénea extracción socioeconómica, gracias a la extensa latitud cubierta por la educación pública. Y, cuando los que ayer habían sido detractores del Gobierno dictatorial y críticos acérrimos de los cambios en educación, ahora hacían suyo este logro del sistema universitario privado y libremercadista, era difícil no ver en esa proclama un reconocimiento al éxito de este nuevo sistema. Quizás también era obvio, excepto para quienes no quisiéramos ver, que podíamos albergar pocas esperanzas de que se revirtiera el rumbo señalado por el régimen dictatorial en 1981, así como dónde estaban las insospechadas simpatías de muchos políticos, y qué era lo tan simpático que despertaba esas simpatías, y por último, qué poco podían esperar las universidades públicas del Estado chileno. 


\section{LA DICTADURA IDEOLÓGICA}

Así como en un totalitarismo estatista es castigado quien intente escapar a la lógica del colectivo, en la dictadura ideológica neoliberal a la cual hemos sido sometidos, todo aquello que no busque lucro o beneficio personal es considerado como intrínsecamente disfuncional al bien social. Parte importante de la dictadura ideológica es que quienes no tienen el don de la sensibilidad social puedan impedir que quienes sí lo tengan puedan expresarlo. Se pretende una generalización y homogenización de las falencias afectivas.

La educación universitaria pagada ha de contribuir a esta nueva ideología individualista enfatizando que el título profesional es un logro propio, una inversión que conllevó sacrificios económicos que deben reembolsarse mediante los beneficios que trae el ejercicio profesional. Notable diferencia con una ideología de educación gratuita que generaba una deuda más intangible, más cálida y más emocional entre el beneficiario y la sociedad que le había permitido educarse, lo cual se expresaba en un natural compromiso de servicio público. El compañero de curso pasó a ser un competidor y potencial rival. El éxito de cada uno se basaría en su propio esfuerzo defendiendo sus intereses personales, tal como habría de enfocarse ahora la previsión o la salud. Curiosamente las autoridades confiesan extrañarse de que los profesionales de la salud recién recibidos se resistan a trabajar en lugares periféricos o alejados. Pero, ipor qué habrían de sentirse impulsados a hacerlo si no solo no recibieron apoyo de la sociedad, sino que más aun están endeudados y sienten que pagar esa deuda (pecuniaria, no afectiva, obviamente) es su necesidad prioritaria? Incluso compromisos ulteriores con el Estado pueden ser sospechosos. Por ejemplo, para un médico, en vez de ejercer algunos años en un lugar apartado para posteriormente ser recompensado con una beca de especialista, puede resultar preferible empezar endeudándose con un banco para pagar una especialización, cosa de, en seguida, quedar libre para ejercer en el mundo privado. La negación brutal del concepto de bien común comienza a diseminarse por cada rincón de nuestras interacciones sociales. Cualquier sociedad considera, por ejemplo, que garantizar atención médica al conjunto del país, así como desarrollar un plan equilibrado de formación de especialistas, es una responsabilidad que compromete al conjunto de la sociedad. Las implicancias de tal responsabilidad pueden llevar, por ejemplo, a asegurar con financiamiento público la formación de especialistas en centros universitarios de alto nivel. Estos centros, a su vez, son considerados parte de un patrimonio nacional, que debe ser preservado y estimulado por el aporte fundamental que representan para la investigación, la innovación en modelos de atención, el desarrollo tecnológico, la cobertura por telemedicina. Solo el fanatismo obcecado que hemos conocido en Chile puede concebir que el avance de la medicina y del sistema de atención en salud vaya a ser el resultado espontáneo de individuos que buscan maximizar sus utilidades. En el modelo chileno, sugerir que el conjunto de médicos especialistas constituyen un bien común para el país constituiría un pensamiento aberrante.

A la Universidad de Chile su vínculo con el Estado le otorga un rol definitorio. Nosotros siempre hemos pensado que esta Universidad no es una Universidad más, que tiene 
una misión y una visión propia que surge de su muy señalado vínculo con el Estado chileno. Para los ideólogos postgolpe, y hasta hoy, explícitamente resulta deseable que la Universidad de Chile siga siendo una buena Universidad, tal vez la más importante, aunque razonablemente no la más importante en todo, pero definitivamente una Universidad más. El mismo afán deseable de la competencia entre individuos es válido para las universidades como instituciones. La entrega de fondos directos del Estado constituiría una distorsión indeseable. La autonomía universitaria, expresada en las prioridades, modalidades y áreas donde una Universidad pública estratégicamente orienta sus esfuerzos, efectivamente se termina. Lo que se busca ahora es que la Universidad deba estar inmersa en el mercado, hiperacúsica a los requerimientos empresariales. Nótese además que este énfasis en la competencia pretendía romper con una de nuestras más nobles tradiciones y tareas históricas de la Universidades en Chile: no solo no haber competido, sino, por el contrario, haber generosamente ayudado al desarrollo de muchas otras universidades en el país. No me refiero a las sedes regionales que le fueron cercenadas, las que no corresponden a esa descripción, sino al rol que cupo a la Universidad en la creación de carreras en otros planteles, por ejemplo, la colaboración con las universidades Católica y de Concepción en la creación de sus respectivas carreras de medicina.

Son múltiples las razones históricas y universales por centrar y articular el sistema educacional en torno a una columna vertebral otorgada por la educación pública. En el caso de Chile, esta ha sido desde siempre considerada como uno de los principales elementos de ecualización y reparación social. Hasta hoy, y quizás especialmente hoy por la inédita segregación a la que el país se ha visto sometido, para muchos jóvenes el ingreso a la Universidad de Chile representa la primera oportunidad en su vida de conocer a jóvenes de nivel socioeconómico, antecedentes étnico-culturales, origen geográfico o ideología política diferentes a los de ellos. Descubren recién entonces que hay chilenos que viven conforme a cánones o condiciones insospechadas. Por otra parte, una educación pública gratuita proporciona indirectamente el mejor control de calidad para el sistema educacional en su conjunto: si alguien opta por el sistema privado que sea por un mérito específico excepcional que este le ofrece, no porque el sistema público sea tan insuficiente que no deja alternativa.

La dictadura ideológica alcanza su expresión más indecorosa y virulenta en la relativización de qué es lo que es verdad y qué es lo que es mentira. Tras el Golpe, se hizo habitual escuchar de planes secretos exterminadores o de personas que huían de sus captores obligando a estos a matarlos. Progresivamente la mentira pareció pasar a cumplir otro rol: destacar el poder absoluto del Gobierno militar. Nada más efectivo para asentar una omnipotencia que una mentira "imperfecta", que obviamente es mentira para quien la escucha, pero que la población tiene que aceptar como verdad. Un integrante de la Junta en algún momento afirmó que el autor de la muerte de tres militantes comunistas era el comunismo internacional, enojado porque a esos tres militantes les había ordenado derrocar al Gobierno militar chileno y no habían tenido éxito en el cumplimiento de la orden. Yo había leído un argumento parecido, pero referido a la organización ficcional Spectre, en una novela de Ian Fleming. En la Universidad bien podríamos empezar a preguntarnos, ¿qué es la verdad? ¿Existe? 
La dictadura ideológica se expresa no solo en la existencia de una sola "verdad", sino en la extrema pobreza intelectual con que esta es presentada. Y quizás, a propósito. Umberto Eco describe que en su infancia al finalizar la guerra, tras la liberación de la ciudad en que vivía, lo que más le impresionó no fue ver que en vez de un único periódico había una gran cantidad y variedad de ellos, sino que, al abrirlos y leerlos, aparecía una infinidad de palabras que portaban una miríada de matices y significados. Eco reflexiona que una dictadura no solo presenta una verdad única, sino que debe hacerlo en blanco y negro, sin matices (REF. 6). El empobrecimiento intelectual parecía constituir un requisito para la dictadura ideológica. En Chile, el empobrecimiento es más amplio y abarcador, la multidimensionalidad inherente a cualquier actividad social habría de verse reducida al dinero y al lucro como únicas medidas de todas las cosas, desde el arte y las noticias deportivas (que ahora desproporcionadamente versan sobre transacciones comerciales de personas) hasta la educación y la salud. En una cuestión afín, el excesivo énfasis en reemplazar la capacidad de juicio global por la medición de indicadores, termina por fetichizar a estos de modo tal que las personas e instituciones se uniformizan y comienzan a marchar al son de los indicadores. Nadie duda que toda institución, persona y actividad deban ser evaluadas, y que esa evaluación deba ser objetiva, pero eso es distinto a renunciar al uso del buen criterio y de la contextualización, reemplazándolos por cortocircuitos de validación.

Pero por sobre todo debo insistir en el postulado de que el modelo impuesto en Chile requiere para su instauración una dictadura total, y para su perpetuación, al menos de una dictadura ideológica. Esa mantención requirió relativizar los excesos del régimen militar con fórmulas del tipo "justicia en la medida de lo posible" y a preservar el autoritarismo y la homogeneidad de la autoridad política mediante el sistema electoral binominal. Más sorprendente aun, el retorno a la democracia, a diferencia de las consideraciones que hacía Umberto Eco, conllevó paradojalmente una restricción aun mayor de la libertad de prensa. Las revistas opositoras que eran toleradas por Pinochet no lo fueron por los gobiernos democráticos. Juan Pablo Cárdenas, periodista que en dictadura mostrara una valentía excepcional, habría de narrar este insólito devenir de la prensa chilena, a partir de sus propias vivencias.

\section{AGRUPÁNDONOS PARA RESISTIR Y PRESERVAR NUESTROS PRINCIPIOS}

Quisiera testimoniar un profundo afecto y sentido de pertenencia hacia dos instituciones en las que participaríamos quienes nos oponíamos a los cambios que el régimen militar perpetraba en el país. Percibíamos que estos cambios remecían nuestro ámbito intelectual, a la vez que valorábamos altamente los principios de convivencia que habían guiado a Chile antes de la dictadura, los que queríamos ver restaurados.

En primer, lugar, la Asociación Universitaria y Cultural Andrés Bello que, bajo la dirección de Jorge Millas y Luis Izquierdo, arranca con la década de 1980. Esta representó un espacio de enorme valor intelectual y emocional para quienes necesitábamos hablar de lo que ocurría en las universidades chilenas y defenderlas del embate al que 
eran sometidas. Esta instancia no solo permitió hermanarnos en la coyuntura, sino que de su reflexión surgieron propuestas que habrían de germinar más tarde. Un ejemplo es el desarrollo, a partir de la experiencia de la Reforma, del concepto de Senado Universitario, iniciativa en la que cupo un rol notable a Luis Izquierdo y Francisco Brugnoli.

La otra institución fue la Asociación de Académicos de la Universidad de Chile, cuyo consejo normativo constituimos en marzo de 1984 eligiendo como primer presidente a Patricio Basso. Esta asociación habría de jugar un rol substancial en conducir a la recuperación de la Universidad de Chile para su comunidad. Su actividad es indisociable de grandes logros del momento, como la primera elección postgolpe de un Decano, Atilano Lamana en Ciencias Físicas y Matemáticas, la participación de la Universidad en la época de las protestas y de la Asamblea de la Civilidad, y, desde luego, la resistencia a Federici (REF. 7). Muchos de sus dirigentes sufrieron exoneraciones temporales, como también le había ocurrido a Luis Izquierdo, siendo secretario de la Asociación Andrés Bello, por declaraciones dadas a la prensa. En julio de 1985 la Asociación convoca a la primera consulta a los académicos de la Universidad de Chile: “Considera usted necesario modificar los estatutos de la Universidad de Chile, a objeto de permitir la participación orgánica de los académicos en la toma de decisiones y en la generación de las autoridades?". Votaron más de 3.000 académicos.

\section{LUZ DE INVIERNO}

A cuarenta años, se puede mirar retrospectivamente no solo la defensa de la Universidad ante la embestida del régimen dictatorial, sino también lo que habría de venir después. El período de resistencia al régimen fue un tiempo de compromiso, fraternidad y reafirmación de principios e ideales. Lo que defendíamos era demasiado importante para nosotros, había que preservar un país al que queríamos entrañablemente y al que sentíamos debernos. Teníamos que recuperarlo y entregarlo a las generaciones venideras restaurando los valores que constituían su identidad histórica. Con el rechazo a la reelección de Pinochet en 1988 pensábamos que habíamos triunfado quienes fundamentábamos dos líneas éticas: "Por una parte la valoración de la institucionalidad chilena que se percibía que el régimen de entonces intentaba socavar (en particular la universitaria, pero explícitamente se extendía a toda la educación, a la salud, a la justicia, y en general a la sociedad civil chilena) y, por otra, la crítica a los cambios introducidos por el régimen, los que en su aspecto más concreto representaban la minimización de muchas de las Universidades tradicionales, coherente con la abdicación estatal a continuar con un rol preponderante en la educación chilena" (REF. 8)

Inmediatamente después del plebiscito de 1988 nadie hubiera querido dar excusas para volver a una dictadura, por lo que la prudencia exhibida por el primer Gobierno elegido parecía comprensible. Distintas se tornaban las cosas para la segunda elección presidencial, donde el slogan "para los nuevos tiempos" aludía a una zeitgeist que invocaba una cierta autocomplacencia, un cierto grado de autoindulgente narcisismo. Más aun, el comienzo de los nuevos tiempos podría estarse refiriendo a 1994, o quizás a 
unos pocos años antes, o más bien a varios años antes. Se comienzan a escuchar asertos como "el legítimo derecho al lucro". Pero a esa evolución simple desde la prudencia hacia la complacencia habría de seguir la transición de la complacencia al liderazgo, es decir, a la cabal toma de posesión del puente de mando de esta nave que surcaba mares mostrándole al mundo un nuevo modelo de sociedad en todo su esplendor. A mayor abundamiento, el tercer Gobierno post-dictadura lo habría de encabezar uno de los intelectuales chilenos de más alto vuelo y, desde luego, vinculado de por vida con la Universidad de Chile. Si tampoco entonces se habrían de visualizar cambios, entonces era como para escribir en las puertas del país la frase inscrita en la puerta al infierno de Dante: "Lasciate ogni speranza, voi ch'entrate" ("Abandona la esperanza si entras aquí").

Y este es un primer considerando que podríamos postular acerca de las razones para la actual crisis del sistema educacional chileno: quizás, quienes debían reconstruirlo no habrían de comprometerse en esa tarea. Tal vez no estaban en condiciones de hacerlo por la simple razón que ellos ya habrían dejado de creer en el valor intrínseco del discurso intelectual en la estructuración de una sociedad, así como también habrían dejado de creer en los postulados ideológicos que habíamos defendido durante el régimen dictatorial. La situación recuerda a Luz de Invierno, esa película que, se dice, Bergman consideraba la mejor de las suyas. En ella un pastor entiende que en la medida que él ha perdido la fe en Dios, no puede ayudar al atribulado feligrés que le solicita orientación, y mientras se debate en qué hacer, el feligrés ha de optar por un final trágico. El padecimiento del pastor es infinito. En Chile, si fuera cierta esta analogía de "pérdida de la fe", esta no pareció conllevar mayores padecimientos. Nuestros pastores intelectuales orgánicos parecían sumarse con alegría al carnaval de la frivolidad, la liviandad, la banalidad. Parecía pretenderse que esta sociedad fuera dejando atrás las inquietudes intelectuales y se lanzara consensuadamente al consumo, a la política centrada en conflictos menores. Perplejos, vimos cómo quienes esperábamos condujeran, entre muchas otras, la lucha por reconstruir la educación pública, parecían irse transformando en defensores del nuevo orden impuesto en 1980. De las tantas nuevas complicidades, dos nos parecen particularmente descarriadas. Una es hacerse parte de la abolición de toda discusión o debate, pues muchos intelectuales de la coalición gobernante pasaron a concordar con la idea consustancial al régimen anterior de ignorar cualquier planteamiento alternativo al consenso, lo que habría de resultar en una de las dictaduras ideológicas más férreas imaginables. Notable, por ejemplo, recordar una simulación de debate en la prensa entre dos expertos, uno de cada bloque político, en que se transformaba explícitamente en comedia lo que para cualquier persona con un mínimo de sensibilidad ya era una tragedia abiertamente denunciada: la educación pública chilena (y esto acaecía en 2010, a un año de una de las principales movilizaciones estudiantiles). La segunda complicidad fue mucho más desconcertante: las dos coaliciones políticas coincidirían en que la educación era un negocio lucrativo, con integrantes de ambas haciéndose parte de este.

Con el tiempo, el equívoco apotegma "en la medida posible" pasaría a significar una fórmula no ya para salvaguardarnos de lo imposible, sino más bien de lo inconveniente. Y, con un poco más de tiempo, lo que de imposible se había transformado en inconveniente, ahora se aproximaba más a lo indeseable. Pero si abstenerse de hablar de la 
dictadura, de la tortura, de las desapariciones, aparentemente podría parecer sano y cómodo, en realidad resultó profundamente patógeno. Nunca sabremos el precio que nos significó el optar por callar, de no ser capaces de asumir como individuos y como sociedad lo que había sucedido. No puedo imaginar un silencio más activo, más demandante de fuerza y energía que este. No hablar de dictadura, tortura, desapariciones requiere una vigilancia continua, de un control total de la prensa, de múltiples señuelos para los ex-opositores al régimen, de convencerse de que quien reclama conocer el destino de un familiar desaparecido debe ser considerado como un vengativo que obstaculiza la reconciliación entre chilenos. Pero una erosión de nuestra alma individual y colectiva, inasible, progresiva pero, al fin y al cabo, ostensible y certera, infiltraría la forma de hacer política tanto en el contexto nacional como en cada institución local, afectaría la espontaneidad de las relaciones interpersonales, desvirtuaría los valores compartidos. Definitivamente, el nuevo modelo impuesto resulta ser mucho más que un modelo económico, es otra forma de ser, de creer, de interactuar. Otra forma de entender lo que es éxito. Otra forma de entender el acceso a la educación y la salud. Otra forma de reducir la complejidad y multicausalidad de los procesos sociales a simplismos casi infantiles, como por ejemplo, la negativa a ver la obvia multidimensionalidad del problema de la delincuencia, en particular la génesis de la delincuencia juvenil, y afirmar (como empíricamente se demostró falso) que se debía a una ligereza en los mecanismos represivos. Otra forma de manipular el conocimiento científico, como por ejemplo, al intentar hacernos creer que el modelo era la puesta en práctica de una ley de la vida que selecciona los mejores a través de la competencia. Es, en su sentido más amplio, un nuevo paradigma ideológico de sociedad.

El esfuerzo refundacional debería expresarse en un quiebre entre las generaciones pre y postgolpe. Puede ser resultado significativo entonces que, justo a una generación del Golpe, en 1997 los estudiantes hayan impugnado las políticas educacionales y hayan salido a demandar un cambio para la Universidad de Chile, tras constatar que en siete años esta se había alejado muy poco del modelo operante durante la intervención dictatorial. La prensa consideró que las peticiones para un nuevo estatuto por parte de los estudiantes conllevaba una forma de cogobierno imposible de aceptar por cuanto la Ley de Educación de Pinochet expresamente lo prohibía. Al final se aprobó el nuevo estatuto, incluyendo plena participación estudiantil en el Senado Universitario. Quizás la primera hoja que habría de moverse después de tanto tiempo. Posteriormente, nuestro silencio de ciénaga habría de volver a romperse en las manifestaciones estudiantiles de 2006 y 2011.

Al volver a mirar los años de dictadura, nuestro afecto ha de estar por sobre todo con cada mujer y hombre del país que supo mantenerse fiel a las concepciones de interacción social fraterna, de respeto por la vida, de valoración de la democracia y de rechazo al autoritarismo. Estas personas, resistiendo los cantos de sirena de los valores que el nuevo modelo imponía, preservaron los sistemas públicos de salud y educación a través del tejido social chileno. Entre ellas, están académicos, funcionarios y, desde luego, estudiantes de nuestra Universidad que se mantuvieron leales a una concepción de educación pública y a una vocación de servicio público. 
La relación de apego que Chile tiene con la Universidad de Chile es admirable y excepcional. Parece ser un referente ético que el país estima necesario. No sé de otras instituciones que susciten la lealtad de esta. Esta fidelidad ha impedido y sigue impidiendo que nuestra Universidad sea desplazada en su vínculo con otras instituciones públicas o en funciones que tradicionalmente ha cumplido.

Termino invocando un recuerdo de la protesta del 9 de agosto de 1984 denominada "Chile defiende la vida". Una protesta pensada para impedir que continuaran las muertes de manifestantes, que en un año sumaban decenas. Al mediodía cantaríamos Gracias a la vida en todo Chile. Los académicos y funcionarios del INTA (eran muy pocos quienes no participaban) nos juntamos en el patio formando una ronda. En el sitio vecino, se estaba levantando un edificio y los obreros de la construcción se asomaron a mirarnos. En un momento, sorpresivamente uno de ellos descendió de tres saltos para pasarse al patio nuestro, se sacó el casco y se incorporó a la ronda y al canto. Recuerdo también que los organizadores del acto habíamos previsto que quizás debíamos agregar otras piezas musicales para prolongar la convivencia de ese encuentro. Recuerdo que elegimos la "Heroica", esa polonesa en que Chopin llora su patria invadida, celebra su rotunda rebelión, y expresa que, tantas veces como la hagan amainar, habrá de volver a alzarse con un brío inquebrantable.

\section{REFERENCIAS CRÍTICAS}

1. Jadresic, A., Historia de Chile en la vida de un médico, Santiago de Chile: Editorial Catalonia, 2007.

2. Comisión de Solidaridad con Médicos Objeto de Represión, Porque fuimos médicos del pueblo, Santiago de Chile: Ediciones Chile-América CESOC, 1993.

3. Devés, R., Galanti, N., Valenzuela, C. y Vivaldi, E.A., "Academic oppression in Chile", en Nature, No 322(6079), Aug 7 1986, pág. 494.

4. Valdés J.G., La escuela de Chicago: Operación Chile, Buenos Aires: Grupo Editorial Zeta, 1989.

5. Mönckeberg, M.O., La privatización de la universidades: Una historia de dinero, poder e influencias, Santiago de Chile: Editorial Copa Rota, 2005.

6. Eco, U., Cinco escritos morales, Barcelona: Editorial Lumen, 1997.

7. Goic, A., Artículos transitorios, En prensa, Transcribe entrevistas y artículos de revista Cauce No 124, 7 de septiembre 1987; revista Apsi, 5 de octubre 1987; y revista Hoy, julio 1985.

8. Vivaldi, E. A., Nos habiamos opuesto tanto... Anales de la Universidad de Chile, Sexta serie, $\mathrm{N}^{\circ} 1$, septiembre 1995, págs. 101-109. 